\title{
Scrotal self-inflicted gunshot injuries: report of two consecutive cases and literature review
}

\author{
Albert Efiong Ukpong ${ }^{*}$ (D), Okon Edet Akaiso, Elijah Asuquo Udo, Ifiok Udo Essiet, Oto-bong Okpoho Peter and \\ Ifiok Paul Etim
}

\begin{abstract}
Background: Isolated scrotal gunshot injuries are uncommon. Even more so when they are self-inflicted. The extent of the injury is determined by the caliber of the weapon. Established management protocols when followed yields excellent results.

Case presentations: We present two male patients, aged 41 and 51 years old, who sustained gunshot injuries to the scrotum following accidental discharges from hand guns stored in their trouser pockets. The first (41 years) sustained grade 5 American Association for Surgery of Trauma (AAST) left testicular injury and was managed by unilateral orchidectomy. The second (51 years old) sustained bilateral grade 4 AAST testicular injuries and had both testes salvaged by primary repair after meticulous debridement.

Conclusion: Isolated scrotal gunshot injuries can occur when low velocity guns are placed adjacent to the genitalia and accidentally discharged. The testes are endangered and can be devitalized requiring orchidectomy or salvaged by meticulous debridement and primary repair when viability is not compromised.
\end{abstract}

Keywords: Scrotum, Gunshot injuries, Self-inflicted, Orchidectomy, Testicular salvage

\section{Background}

The external genitalia, particularly the scrotum, is situate between the thighs and is usually heavily clad and hidden which confers on it protective shielding from external gunshot assaults $[1,2]$. This explains their uncommon occurrence. $10 \%$ of all civilian gunshot wounds (GSWs) involves the genitourinary system $[3,4]$. Of these $2-4 \%$ affects the external genitalia $[4,5]$. Even more uncommon are GSWs involving the scrotum only. However, rising insecurity and civil violence promotes possession of guns by untrained individuals, concealed in trouser pockets, for self-defence. This makes the genitalia vulnerable to injuries when the trigger is inadvertently pressed and discharged- a case of "self-defence" turned to "selfdestruction" or "self-affliction". The extent of injury is

\footnotetext{
*Correspondence: albertukpong@uniuyo.edu.ng; dralbertukpong@yahoo. com

Urology Division, Department of Surgery, University of Uyo Teaching Hospital, PMB 1136, Uyo, Akwa Ibom State, Nigeria
}

determined by the velocity, structure and integrity of the projectile from the gun, and the distance from the muzzle to the target [6-8]. Thus, isolated scrotal gunshot injury scenarios occurring at very close range are predictive of the caliber of the weapons being of low-velocity [9].

Management of penetrating scrotal injuries involves prompt surgical exploration, meticulous debridement and primary repair of injured tissues $[6,7,10]$. The goal is to retain as much viable tissues as possible, in order to preserve androgenic and spermatogenic functions, as well as cosmetic appearance. The American Association for the Surgery of Trauma (AAST) Testicular Injury Scale is a useful guide for peri-operative evaluation, categorization and treatment of these injuries [11].

We describe the presentation and management of two consecutive cases of isolated scroto-testicular injuries caused by accidental discharges from hand-guns stored in trouser pockets of the patients. The involvement of the scrotum and testes only, sparing the penis, at such close range, is unique and rare. 


\section{Case presentations}

\subsection{Case summary 1}

A 41-year-old man presented with a 2-h history of gunshot injuries to the left hemi-scrotum and left upper thigh. This occurred following an accidental discharge from a gun carried in his right trouser pocket. The bullet pierced through the left hemi-scrotum and got lodged in the left upper thigh, resulting in left hemi-scrotal swelling and bleeding from the wounds. He could bear weight on the left lower limb and walk with support. Pre-morbid status was normal and he's married with children. On examination, he was fully conscious, alert and hemodynamically stable. Chest, abdomen and pelvis were grossly normal. External genitalia showed a swollen dark colored left hemi-scrotum with entry and exit wounds on its anterior and lateral surfaces. There was tenderness and bleeding from the wounds. The right hemiscrotum, testis, penis and urethra were all normal. The adjacent left upper thigh disclosed a $2 \mathrm{~cm}$ entry wound oozing blood. A diagnosis of scrotal self-inflicted gunshot injury with associated left thigh injury was made. Scrotal ultrasound scan demonstrated preserved integrity of the tunica albuginea and blood flow on the right testis while these were absent on the left. An X-ray of the left thigh showed a bullet lodged in the soft tissues (Fig. 1). He was resuscitated and promptly taken for scrotal exploration, where the major findings included: left hemi-scrotal hematoma, shattered and necrotic testis and epididymis (AAST grade 5 Testicular injury). Left orchidectomy, debridement and primary closure of scrotal wounds,

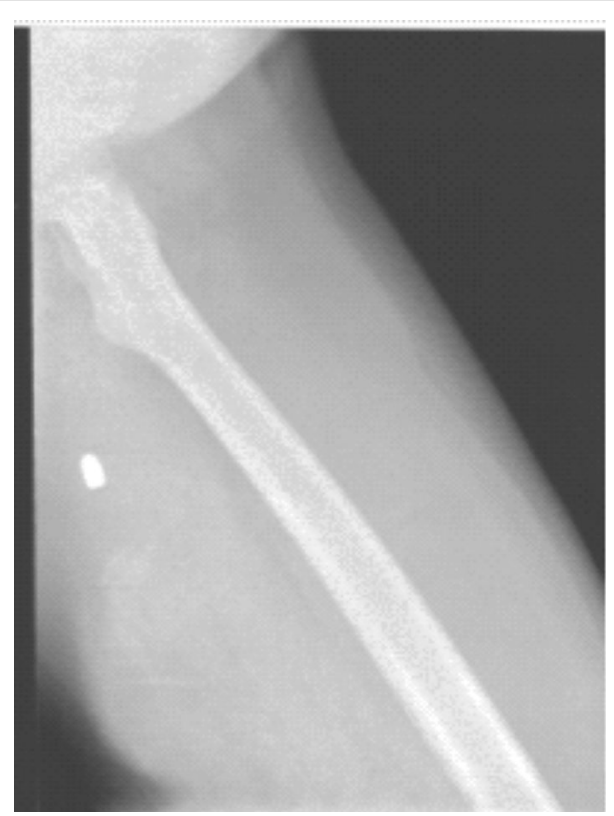

Fig. 1 X-ray left thigh showing radio-opaque bullet in soft tissue and debridement followed by daily dressings of the thigh wounds, were the procedures carried out. Wounds healed without complications and patient was discharged on the $18^{\text {th }}$ day post-op. At one year follow-up, he was satisfied with his erectile function, and had no plans to have more children.

\subsection{Case summary 2}

A 51-year-old male security operative presented with a $3 \mathrm{~h}$ history of injury to the scrotum, bleeding, pain and associated injury to the left thigh, following an accidental discharge from a shot gun stored in his right trouser pocket. Pre-morbid status was normal and he was married with children. Examination revealed a patient that was conscious, alert with stable vital signs. The external genitalia demonstrated scrotal lacerations with ruptured tunica albuginea and prolapse of seminiferous tubules of both testes. Again, the penis and urethra were spared. There was associated avulsion of skin of upper medial part of the left thigh (Fig. 2a). A diagnosis of Scrotal self-inflicted gunshot injury was made. X-ray of the left thigh showed multiple pellets lodged in the soft tissues, without bony involvement. At exploration and debridement, $40 \%$ of the extruded seminiferous tubules were adjudged viable (bilateral AAST grade 4 Testicular Injuries). Primary repair of the testes and scrotum was carried out with good cosmetic appearance (Fig. 2b and c). A month follow-up showed moderate testicular atrophy and patient was satisfied with his erectile function, and had no plans of future child bearing.

\section{Discussion}

The external genitalia constitute $1 \%$ of the total body surface area and receives relative protective shield from the thighs against external gunshots. When the guns are stored in trouser pockets or waist band, the genitalia become exposed and vulnerable to accidental discharges and such are said to be self-inflicted $[5,6,12]$. This has been attributed to improper handling and use of guns [5]. Genital gunshot wounds are rare and constitutes $<1 \%$ of all gunshot injuries [13]. The self-inflicted variety involving only the scrotum and contents can be said to be very rare.

Knowledge of GSW ballistics is vital to proper evaluation and management of these injuries. It has been observed that the extent of the injury is determined by the velocity of the projectile, its structure, integrity and the distance from the gun to the target $[6-8,14]$. Thus, the higher the velocity, and the closer the target, the more extensive the injury [14-16]. Therefore, going by the extent of injuries observed in the two patients, it can be deduced that the guns were of the low velocity caliber $(200-300 \mathrm{~m} / \mathrm{sec})$. 

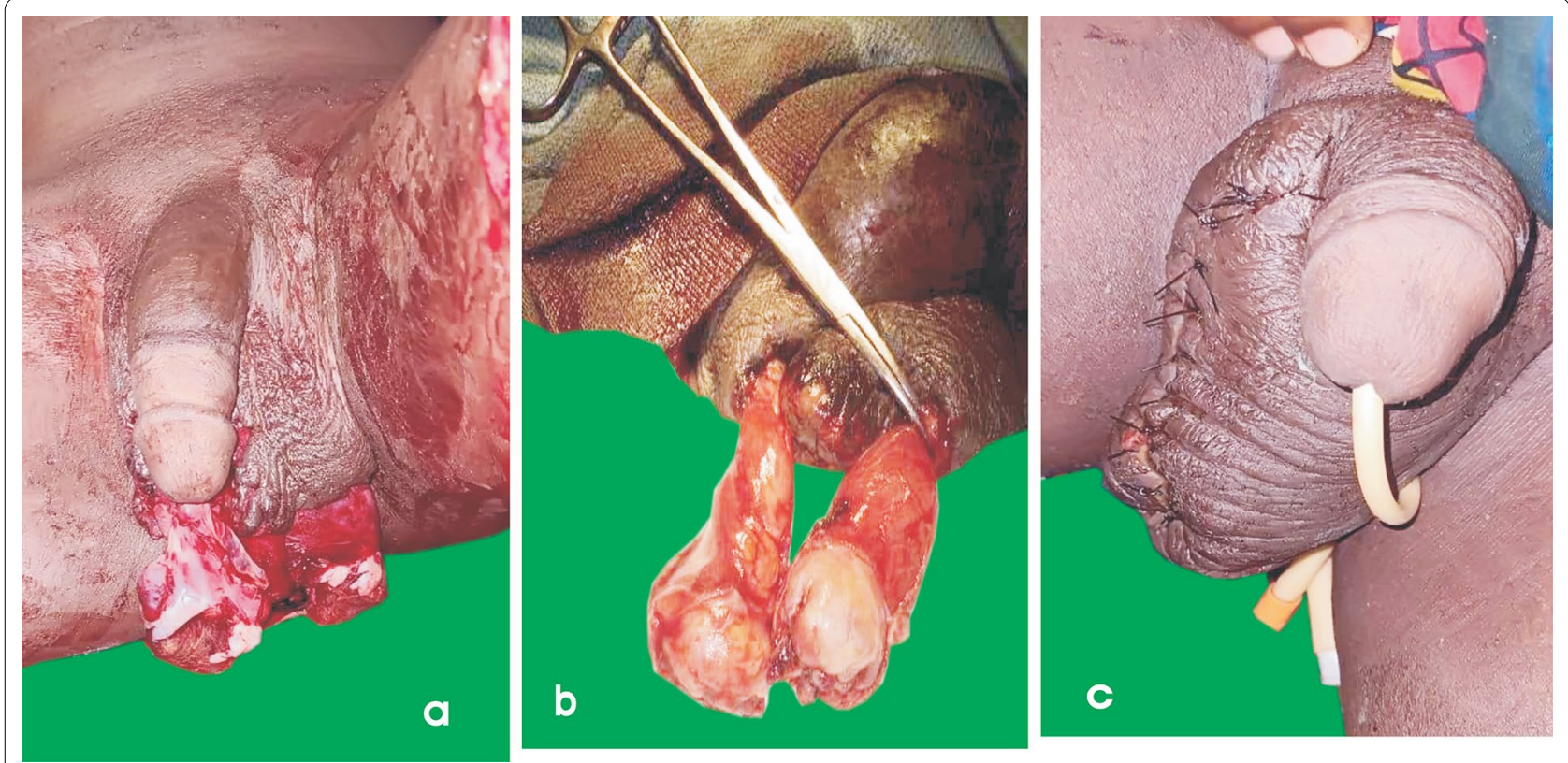

Fig. 2 a Grade 4 AAST Testicular injuries with extruded seminiferous tubules. b Repaired testes after meticulous debridement c Post-operative repair appearance

In standardizing the evaluation of injury severity, the American Association for the Surgery of Trauma (AAST) designed a testis injury scale in 1995 [11]. It is graded from I-V, with grades III, IV, V, representing laceration of the tunica albuginea with $<50 \%$ parenchymal loss; major laceration of the tunica albuginea with $50 \%$ or greater parenchymal loss; and total testicular destruction or avulsion, respectively. Patient 1 in this report sustained unilateral grade $\mathrm{V}$, while patient 2 sustained bilateral grade IV injuries. The grade $\mathrm{V}$ injury involved the left testis similar to that recorded by Obi et al. [12]. Bilateral testicular injuries are rare [6, 17]. Gomez et al. [17] and Sinham et al. [10] in their series of 23 and 97 patients with genital gunshot injuries reported bilateral testicular injuries in 1 and 6 patients, respectively.

The anatomic domiciliation of civilian GSWs of the external genitalia follows no predictable pattern. However, there seems to be a preponderance of scrotal over penile injuries in most series $[4,10,13,14,17-19]$. Conversely, penile injuries predominate in a few series $[20$, 21].

The approach to the management of these patients includes brief ample and ballistic history [6-8, 17, 21], detailed general and genital examination with a view to determining urgency of surgical intervention [6]. Associated extragenital injuries should be noted and given attention, as injury to major vessels can result in fatality [8]. The commonest associated injury as demonstrated in this report and by most authors is injury to the lower extremity $[5,8,10,12,14,22]$. Our index patients had associated injuries to the left thigh. This is explicable as the guns were stored in the right trouser pockets with the muzzle facing the left thigh. Scrotal ultrasonography is the main investigative modality and is useful in assessing tunical integrity and testicular blood flow in equivocal cases or of a contralateral uninjured testis $[6$, 11]. The first index patient disclosed these signs on the right testis while the left was adjudged non-viable. Where the seminiferous tubules are extruded from ruptured tunica albuginea, assessment is best carried out on table [6]. In our second patient, scrotal ultrasound scan was unnecessary.

Definitive treatment for penetrating scrotal injuries consists of emergency scrotal exploration, meticulous debridement and primary repair of injured testis and scrotum $[6,10,13,14,17,23,24]$. The commonest surgical procedure carried out for scrotal GSWs in one series was repair of lacerations of testis or scrotum [13].When this is done, testicular salvage rate of $35 \%-75 \%$ has been recorded by most authors $[6,8,10,13,14,16,18,20]$. In this series, out of three (3) testes injured, two (66.7\%) were salvaged by primary repair alone. Where the testis is viable but primary approximation, due to deficiency of the tunica albuginea is not feasible, tunica vaginalis graft can be used to interpose the defect and effect a repair $[15,23,25,26]$. For devitalized, non-viable testes, orchidectomy is the treatment of choice. In one large series, orchidectomy rate of $48 \%$ was recorded [10]. This 
is consistent with orchidectomy rate of $23 \%-55 \%$ in most series [10,13,17]. Most orchidectomies carried out for genital GSWs are unilateral [27], and this is exemplified by patient 1 in this report.

\section{Conclusion}

Genital gunshot wounds can be extensive involving both penis and scrotum or confined to the scrotum only. This is contingent on the velocity and caliber of the weapon. The self-inflicted variety results from improper handling of guns tucked in trouser pockets or waistband and the frequency seems to be rising. Observance of the principles of prompt surgical exploration, careful debridement and primary repair of injured testes and scrotum leads to satisfactory outcomes.

\section{Abbreviations}

AAST: American association for surgery of Trauma; GSWs: Gun shot wounds.

\section{Supplementary Information}

The online version contains supplementary material available at https://doi. org/10.1186/s12301-021-00234-x.

Additional file 1. CARE Checklist Information File.

\section{Authors' contributions}

AEU-Conception, data acquisition and collation, literature search and review, manuscript writing and editing, approval of the submitted version, certifies accuracy and agrees to be personally accountable for his contributions; OEA-Data acquisition, literature search and review, manuscript writing and editing, approval of submitted version, certifies to accuracy and agrees to be personally accountable for his contributions; EAU-Data acquisition, literature search and review, manuscript writing and editing, approval of submitted version, certifies to accuracy and agrees to be personally accountable for his contributions; IUE-Literature search and review, manuscript writing and editing, approval of submitted version, certifies to accuracy and agrees to be personally responsible for his contributions; OOP- Data acquisition, literature search, manuscript writing and editing and approval of submitted version; IPE-Data acquisition, literature search, manuscript writing and editing, and approval of submitted version. "All authors have read and approved the final manuscript."

\section{Funding}

We received no external funding for this publication.

\section{Availability of data and material}

Not Applicable.

\section{Declarations}

Ethics approval and consent to participate

The study received approval from the University of Uyo Teaching Hospital Research and Ethics Committee.

\section{Consent for publication}

Written informed consent to publish this information has been obtained from the study subjects.

\section{Competing interests}

We have no competing interests to declare.
Received: 6 July 2021 Accepted: 24 August 2021

Published online: 15 September 2021

\section{References}

1. Dogo HM, Ibrahim AG, Gana YL (2016) Missile Injuries to the external genitalia: a five year experience in Maiduguri, North Eastern Nigeria. Int J Res Med Sci 4(7):2964-2966

2. Osegbe DN, Ekeke ON, Ukpong AE, Adegbola O et al (1999) Genital injuries in Civil Urban Population. Lagos J Surg 2(1):3-10

3. McGeady JB, Breyer BN (2013) Current epidemiology of genitourinary Trauma. Urol Clin North Am 40:323-334

4. Najibi S, Tannast M, Latini JM (2010) Civilian gunshot wounds to the genitourinary tract: incidence, anatomic distribution, associated injuries, and outcomes. Urology 76(4):977-981

5. Mahamat MA, Sougui S, Ouchemi C, Ngaringuem O, Jalloh M et al (2015) Severe external genitalia lesion by firearm: a case report. OPEN JOURNAL OF UROLOGY 5:188-191

6. Goldman C, Shaw N, du Plessis D, Myers JB, van der Merwe A, Venkatesan K (2020) Gunshot wounds to the penis and scrotum: a narrative review of management in civilian and military settings. Transl Androl Urol. https:// doi.org/10.21037/tau-20-1175

7. Genital Trauma- Prof Alessandro Natali. www.profnatali.it

8. Exabbal AM, Hussain FF, Benkhadoura MO, Banni AM (2018) War-related penile injuries in Libya: Single institution experience. Arab J Urol $16: 250-256$

9. Cavalcanti AG, Krambeck K, Araujo A, Manes CH, Favorito LA (2006) Penile Lesion from gunshot wound: a 43-case experience. Int Braz J Urol 32(1):56-60

10. Sinham J, Rothman J, Canter D et al (2012) Gunshot Wounds to the Scrotum: a large single institutional 20-year experience. BJU Int 109:1704-1707

11. Park J-S, Lee S-J (2007) Testicular Injuries-Efficacy of the Organ Injury Scale Developed by the American Association for the Surgery of Trauma. Korean J Urol 48(1):61-65

12. Obi AO, Ulebe AO, Nnadozie UU, Maduba CC et al (2021) Self-inflicted gunshot injury to the external genitalia: a case report and review of literature. Afr J Urol 27:18

13. Grigorian A, Livingstone JK, Schubl SD, Hasjim BJ et al (2018) National Analysis of testicular and scrotal trauma in the USA. Res Rep Urol 10:51-56

14. Brandes SB, Buckman RF, Chelsky MJ, Hanno PM (1995) External Genitalia Gunshot Wounds: A Ten-year experience with fifty-six cases. J Trauma 39:266-272

15. Ahmed $\mathrm{F}$ et al (2020) Use of tunica vaginalis graft for repair of traumatic bilateral testicular rupture after gunshot: a case report. Pan African Med J. https://doi.org/10.11604/pamj.2020.36.268.21988

16. Jenkins PM, Haake RS, Perinjelil V et al (2021) A complex genitourinary injury following gunshot in a 12 year old and systematic review. Urology Case Reports 34:101500

17. Gomez RG, Castanheira AC, MCAninch JW (1993) Gunshot wounds to the male external genitalia. J Urol 150:1147-1149

18. Phonsombat S, Master VA, MCAninch JW (2008) Penetrating external genital trauma: a 30-year single institution experience. J Urol 180:192-195

19. Ahmed A, Mbibu NH (2008) Aetiology and Management of injuries to male external genitalia in Nigeria. Injury 39(1):128-133

20. Ghilan AM, Ghafour MA, Al-Asbahi WA et al (2010) Gunshot Injuries to the male external genitalia. Saudi Med Journal 31:1005-1010

21. Ofoha CG, Shuaibu SI, Onowa VE, Galam ZZ (2018) Contemporary management of genitourinary injuries in a tertiary trauma center in Nigeria. Int J Res Med Sci 6:1134-1138

22. Cerwinka WH, Block NL. Gunshot Injuries of the Penis: The Miami experience. J Urol 2006;175

23. Morey AF, Brandes SB, Dugi DD III, Armstrong JH et al (2014) Urotrauma: AUA Guideline. J Urol 192:327-335

24. Summerton DJ, Djakovic N, Kitrey ND et al (2012) Guidelines on urological Trauma. Eur Urol 62:628-639 
25. Chiancone F, Fabiano M, Langella NA, Sannino S, Fedelini P (2020) Direct gunshot wound to the testicular artery: a rare case report. Ibnosina J Med Biomed Sci 12:320-322

26. Ferguson GG, Brandes SB (2007) Gunshot Wound Injury of the Testis: the use of tunica vaginalis and polytetrafluoroethylene grafts for reconstruc tion. J Urol 178:2462-2465

27. Kadouri Y, Zaoui Y, Sayegh H et al (2021) Scrotal gunshot injury: a case report. Urology Case Reports 34:101437

\section{Publisher's Note}

Springer Nature remains neutral with regard to jurisdictional claims in published maps and institutional affiliations.

\section{Submit your manuscript to a SpringerOpen ${ }^{\odot}$ journal and benefit from:}

- Convenient online submission

- Rigorous peer review

- Open access: articles freely available online

- High visibility within the field

- Retaining the copyright to your article

Submit your next manuscript at $\boldsymbol{\nabla}$ springeropen.com 